\title{
Effect of 4-Allyl-2-Methoxyphenol (Eugenol) on Motor Co-Ordination in Subacute Restraint Stress Induced Wistar Albino Rats
}

\author{
Pandian Selvan, Malathi, Ravindran Rajan* \\ Department of Physiology, Dr. ALM PG Institute of Basic Medical Sciences, University of Madras, Taramani campus, Chennai-600 113, India.
}

\begin{tabular}{|c|c|}
\hline ARTICLE INFO & ABSTRACT \\
\hline $\begin{array}{l}\text { Article history: } \\
\text { Received on: } 15 / 07 / 2016 \\
\text { Revised on: } 12 / 08 / 2016 \\
\text { Accepted on: } 10 / 09 / 2016 \\
\text { Available online: } 29 / 11 / 2016 \\
\end{array}$ & $\begin{array}{l}\text { Eugenol is an allylbenzene class of chemical compounds, used in cosmetic and food products. Being a pro- } \\
\text { oxidant and as an anti-oxidant, used as an essential component of many medicinal herbs. For years, it has been } \\
\text { used in dental practice to relieve pain arising from pulpitis and dentinal hypersensitivity. There are few reports } \\
\text { of anticonvulsant effect, but further effects are less reported. Lack of comprehensive studies and data of eugenol } \\
\text { on the central nervous system effects in animal model thus necessitates further research activities. }\end{array}$ \\
\hline $\begin{array}{l}\text { Key words: } \\
\text { Eugenol, Wistar albino rats, } \\
\text { Immobilization stress, Rota } \\
\text { rod, Staircase, } \\
\text { Narrow beam. }\end{array}$ & $\begin{array}{l}\text { The aim of this study was to observe and evaluate the effect of eugenol on motor coordination in restraint stress } \\
\text { induced rats. Animals were divided into five groups of six animals each. The group I Negative control } \\
\text { (Unstressed, untreated), Group II Positive control (received vehicle PG), Group III treated with Eugenol (150 } \\
\text { mg/kg B.W.), Group IV Restraint stress alone, Group V treated with Eugenol and restraint stress ( } 150 \mathrm{mg} / \mathrm{kg} \\
\text { B.W.), The treatment was given for } 15 \text { days at the end of the } 15^{\text {th }} \text { day plasma corticosterone and rota rod, narrow } \\
\text { beam walk and stair case behavioural parameters have been measured. Significant effects of motor co-ordination } \\
\text { were observed in treated and treated with stress group when compared to positive control groups. This study } \\
\text { shows eugenol to possess improved motor coordination in immobilization stress induced Wistar rats. }\end{array}$ \\
\hline
\end{tabular}

\section{INTRODUCTION}

Stress represents one of the most important influences on behavior, particularly on cognition and emotion (Selye, $1975 a, b)$. Stress can also affect sensory perception and induce analgesia in humans and rodents (Marjan et al., 2012). In line with these findings, evidence suggests that stress adversely affects motor performance in both humans (Maki and McIlroy, 1996) and rodents (Metz et al., 2001). Aside from direct effects of stress hormones on nervous system function, stress-associated changes in emotionality, such as anxiety, also affect motor activity and performance (Lepicard et al., 2000, 2003). It is known that stress and anxiety modulate motor activity in open field tests (Treit and Fundytus, 1988; Liebsch et al., 1998), and exploration in the staircase paradigm. Furthermore, mouse strains

\footnotetext{
* Corresponding Author

Email:dr.ravindranrajan87@gmail.com
}

prone to developing anxiety show greater impairments in a skilled motor task than less emotional mice (Lepicard et al., 2000). Eugenol (4-allyl-2-methoxyphenol), the principal chemical constituent of clove oil and tulsi has been primarily derived from a variety of plant sources, including Eugenia caryophyllus, Oscimum sanctum Linn and Myristica fragrans. For years Eugenol has been used in dental practice to relieve pain arising from a variety of sources, including pulpitis and dentinal hypersensitivity. It is widely used as a flavoring agent in baked foods, beverages, sweets and frozen dairy products and also in cosmetics. In traditional medicine, eugenol has been used in the treatment of flatulence, cholic, chronic diarrhea and other gastrointestinal disorders. It is considered non-mutagenic, non-carcinogenic and generally recognized as safe (GRAS) by the Food and Drug Administration (prakash et al., 2004). In the recent past, a wealth of literature has been generated on Eugenol's antidepressant, antistress, anticonvulsant, and analgesic activities. 
Eugenol is also reported to possess anti-inflammatory, antioxidant, anesthetic and muscle relaxant properties (Irie et al 2004). Although eugenol has been subjected to such vast research by many scientists, the exact mechanism for its mode of neuroprotection against and motor coordination remains unclear. The purpose of this study was to assess the effects of restraint stress on motor coordination and performance in rats after the administration of Eugenol and its protective role after restraint induced stress in albino rats.

Thus the current study is designed to investigate the effects of Immobilization stress and stress-associated hormonal changes and Motor coordination in eugenol treated adult female rats.

\section{MATERIALS AND METHODS}

The study was approved by the Institute's Animal Ethical Committee (IAEC no. 01/17/2015) and the Committee for the Purpose of Control and Supervision of Experiments on Animals (CPCSEA). Experimental animals were all healthy adult female albino rats of the Wistar strain, weighing $150-220 \mathrm{~g}$. All the animal experimentation involved in this work was done in accordance with national and institutional guidelines for the protection of animal welfare.

\section{ANIMALS}

Experimental animals were all healthy adult female albino rats of the Wistar strain, weighing $150-220 \mathrm{~g}$. All the animals were maintained under standard laboratory conditions, housed 3 per cage $(29 \mathrm{~cm} \times 22 \mathrm{~cm} \times 14 \mathrm{~cm})$ and were allowed free access to food and water. Appropriate ethical clearance was obtained for this work from the Institutional Animal Ethical Committee (IAEC no. 01/17/2015 dated 27/02/2014)..

\section{EXPERIMENTAL GROUPS}

Animals were randomly divided into five groups and each group consisted of 6 animals. Eugenol (2-Methoxy-4-[2-propenyl] phenol $\left(\mathrm{C}_{10} \mathrm{H}_{12} \mathrm{O}_{2}\right)$ was purchased from Sigma.

Group I: This group of rats served as control.

Group II: Rats of this group were administrated with vehicle (PG) IP for 15 days.

Group III: animals were administrated with Eugenol (150 $\mathrm{mg} / \mathrm{kg} / \mathrm{day}$, IP for 15 consecutive days)

Group IV: subjected to immobilization stress alone for 15 days (6 $\mathrm{hr} /$ day) and immobilization stress induced changes were observed in this group.

Group V: animals were treated with Eugenol $150 \mathrm{mg} / \mathrm{kg} . b . w t$ along with immobilization stress for 15 days. The rats were trained on a Rota rod, narrow beam, grid runway and staircase for assessment of motor coordination. Behavior activities were recorded on the 15 th day after immobilization stress exposure along with the controls.

\section{Assay of Corticosterone}

This method was carried out with slight modification from (Singh andVerman 2008) and is based on the oxidation of corticosteroids with ferric iron (III) in an acidic medium and subsequent complex with ferrous iron (II) and potassium hexacyanoferrate. $0.5 \mu \mathrm{l}$ of Plasma samples was mixed with appropriate volumes of working solutions of corticosterone were transferred into a series of $10 \mathrm{ml}$ volumetric flasks. Sulphuric acid (4N, $2 \mathrm{ml})$ and ferric chloride $(0.5 \%, 2 \mathrm{ml})$ were added to each followed by potassium hexacyanoferrate (III) solution $(0.5 \%, 0.5$ $\mathrm{ml})$.

The mixture was heated in a water-bath maintained at $70 \pm 2^{\circ} \mathrm{C}$ for 30 minutes with occasional shaking and diluted to the $5 \mathrm{ml}$ mark with distilled water. The absorbance was measured at $780 \mathrm{~nm}$ against the reagent blank.

\section{IMMOBILIZATION STRESS INDUCTION PROCEDURE}

Rats were subjected to restraint stress in a wire mesh restrainer (Fig. 1.) for 6 hours per day for 15 days. The wire mesh restrainer had a wooden base and stainless steel wire mesh restrainer hinged to the base. The restrainer having the dimensions of $8 \mathrm{~cm}(\mathrm{~L}) \times 4 \mathrm{~cm}(\mathrm{~B}) \times 4 \mathrm{~cm}(\mathrm{H})$ was used for the experiments. A padlock and latch helped to secure the rat in the restrainer.

\section{Rota Rod Test}

Motor coordination was assessed using the conventional Rota rod test (Dunham and Miya, 1975) the apparatus consisted of a horizontal iron rod, $2.5 \mathrm{~cm}$ in diameter and $15 \mathrm{~cm}$ long, with a roughened surface moving on its axis at $10 \mathrm{rpm}$. Rats were trained for 5 min consecutively for a week before the rats were tested by recording.

The duration for which the animal was able to balance on the moving rod (until it fell) was noted as the co-ordination time. The results of the three trials were averaged to give a mean latency of Motor co-ordination.

\section{Narrow beam-walk}

Animals were trained to rapidly cross an elevated wooden beam. The beam was $2.5 \mathrm{~cm}$ wide and was elevated to a height of $1 \mathrm{~m}$ above the floor. (Kolb and Whishaw, 1983) Each test session consisted of three trials in which latency to cross the beam and the number of foot faults was observed. Following training, the rats were tested by recording the time it took to cross the beam. Rats will normally walk with their feet flat on the surface of the beam.

Therefore, a fault was defined as any use of the forelimb or hind limb on the side of the beam, or if either foot slipped off the top surface of the beam. The results of the three trials were averaged to give a mean latency and a foot fault score. 


\section{Staircase}

The apparatus consisted of a Plexiwooden enclosure (47 x $10 \times 25 \mathrm{~cm}$ ) with identical steps. The only light source in the room was a 60 watt desk lamp above the staircase (Simiand et al., 1984). The animals were individually placed on the floor of the box. The animal was placed individually on the floor of the box with its back to the staircase. The number of steps climbed and the number of rears was counted over a five minute period. A step was considered to be climbed only if the rat had placed all four paws on the step. The number of steps descended was not taken into account. After each animal had been tested, the box was rapidly cleaned to eliminate any olfactory cue which might modify the next animal's behavior.

\section{Statistical Analysis}

The statistical software package SPSS 10.0 for windows was used to analyze the data. A statistical analysis was undertaken by using ANOVA Tukey's multiple comparison tests. $\mathrm{P}<0.05$ was considered statistically significant.

\section{RESULTS}

\section{Changes in Corticosterone Levels}

Plasma corticosterone levels were evaluated in all the experimental groups. In stress-group, Plasma corticosterone levels were significantly increased when compared to the control and treated groups. Whereas in case of stress with eugenol treated group shows significant decrease $(\mathrm{p}<0.05)$ when compared to stress alone group. This indicates that eugenol has anti stressor activity (Fig. 1).

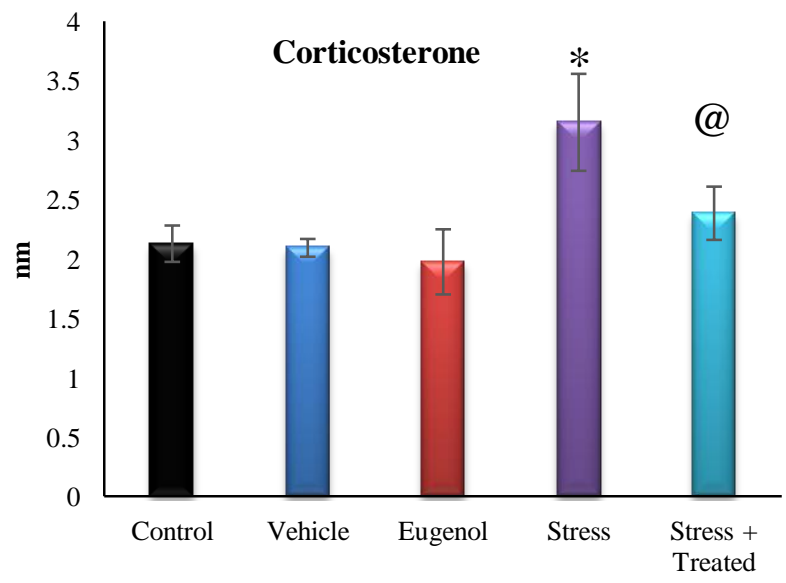

Fig. 1: Effect of Plasma corticosterone on restraint stress induced animals. Values are expressed as Mean $\pm \mathrm{SD}, \mathrm{N}=6 . *$ compared with saline control; @ compared with stress. The symbols represent statistical significance: $*, @<\mathrm{P} 0.05$

\section{ROTA ROD}

\section{Rota rod Time Taken}

When compared to control and vehicle, restraint stress group shows significance reduction in rota rod performance, whereas in case of stress with treated group shows significant increased $(\mathrm{p}<0.05)$ performance when compared to stress alone group. This indicates that eugenol has increased the motor coordination in stress with treated group (Fig. 2).

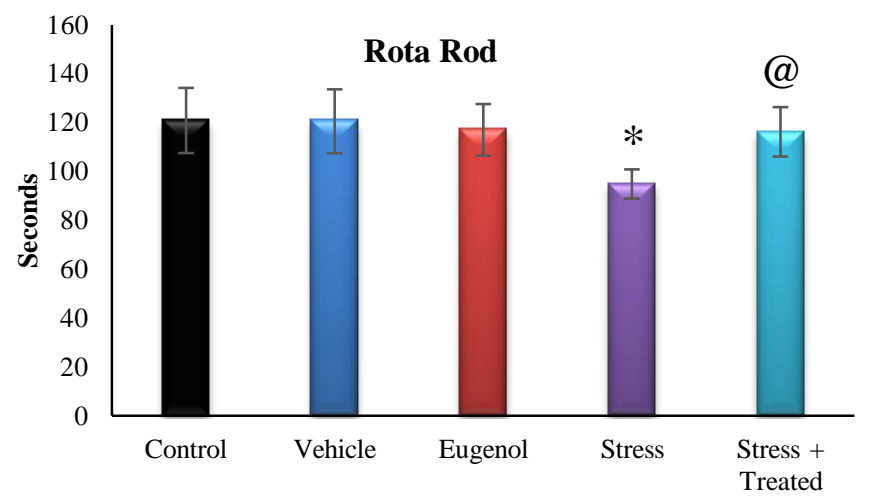

Fig. 2: Effect of restraint stress on Roto rod performance. Values are expressed as Mean $\pm \mathrm{SD}, \mathrm{N}=6$.* compared with saline control; @ compared with stress. The symbols represent statistical significance :*,@< $\mathrm{P} 0.05$.

\section{NARROW BEAM}

\section{Narrow Beam Time Taken}

Time taken in the narrow beam test has been increased significantly $(\mathrm{p}<0.05)$ in restraint stress group when compared to control, vehicle and treated alone groups. The numbers of slips has been increased in the stress alone group when compared to other groups (Fig. 3).

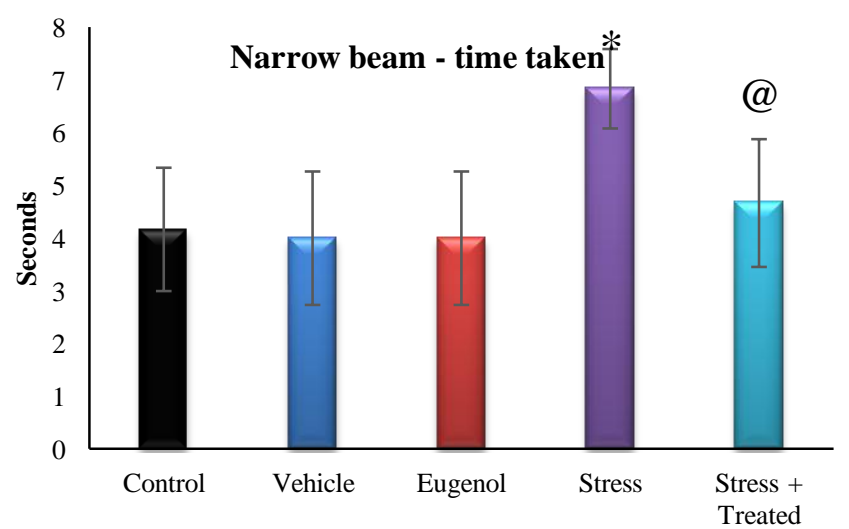

Fig. 3: Effect of restraint stress on Narrow beam time taken .Values are expressed as Mean $\pm \mathrm{SD}, \mathrm{N}=6$.*compared with saline control; @compared with stress. The symbols represent statistical significance : *, @ $<$ P 0.05 .

\section{STAIR CASE}

Staircase behavior shows that number of climbing of steps has been reduced in stress group alone when compared to vehicle, control and treated group. Whereas, stress with treated group shown that significant increase in climbing activity equal to that of control group (Fig. 4). 

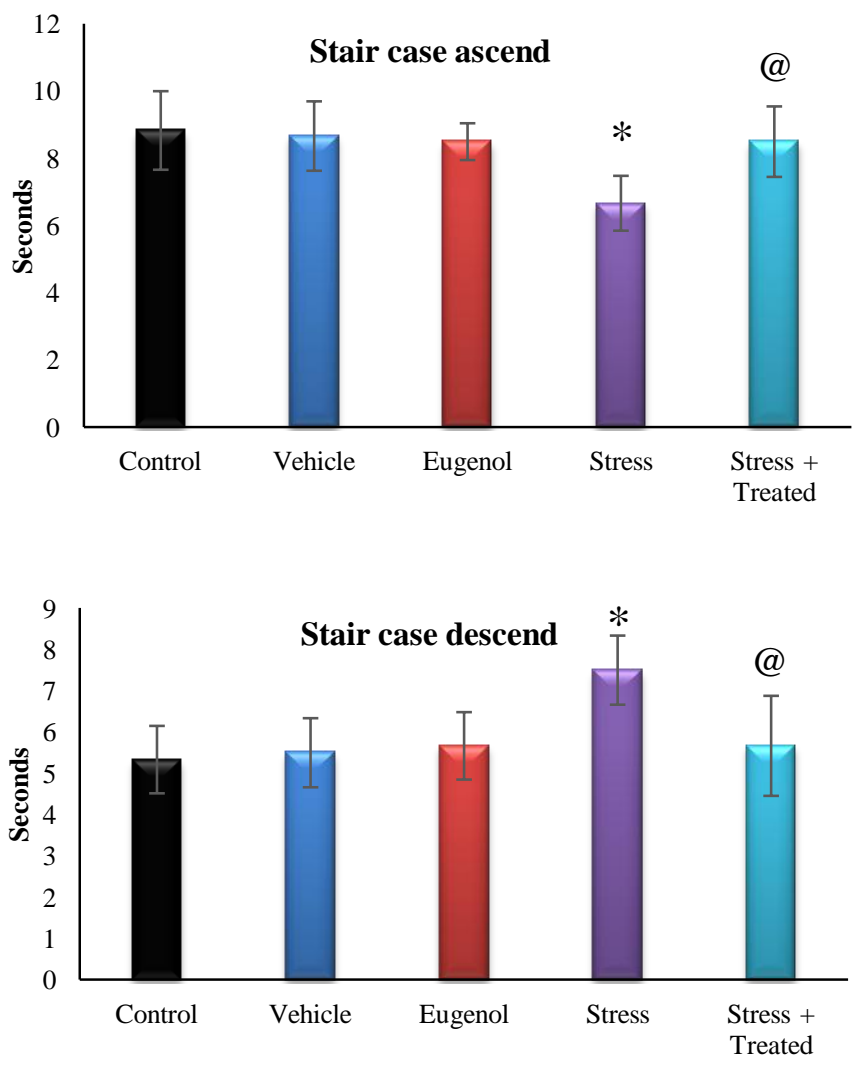

Fig. 4: Effect of restraint stress on Stair case ascend and descend .Values are expressed as Mean $\pm \mathrm{SD}, \mathrm{N}=6$.*compared with saline control; @ compared with stress. The symbols represent statistical significance :*,@< P 0.05 .

\section{DISCUSSION}

Medicinal herbs constitute the cornerstone of traditional medical practice worldwide. The majority of the population in developing countries remains dependent on them for health care (Amos et al., 2001). Eugenol is a constituent of many medicinal herbs and also reported to possess several activities (Laekeman et al., 2006; Muller et al., 2006). In traditional medicine, it is used against gastrointestinal disorders such as flatulence and chronic diarrhea (Pruthi et al., 1976). In addition, a study has shown that it can be used in the treatment of vaginal candidiasis as well (Chami et al., 2004).

Recent findings indicate that stress and stress hormones affect motor function. Parts of the motor system, such as the striatum and motor cortex, have a considerable glucocorticoid receptor density that renders them susceptible to the effects of stress. This is reflected by observations that psychological stress and glucocorticoids induce impairments of normal motor performance (Metz et al., 2005). Furthermore, a considerable body of evidence indicates a link between symptoms, pathology and stress in Parkinson's disease. While this condition is multifactorial, stress seems to play a key role in its pathology as well as in other neurodegenerative events on the motor system.

The mechanism underlying stress-induced tissue damages are not yet fully understood, however, accumulating evidence has implied that the production of free radicals plays a critical role in these processes. Previous studies have indicated that stress stimulated numerous pathways leading to increased levels of free radicals. Oxygen radicals can attack proteins, nucleic acids and lipid membranes, thereby disrupting cellular functions and integrity (Swaroopa and Sathyavelu, 2012). Brain is the target for different stresses because of its high sensitivity to stress induced degenerative conditions. Recent findings indicate that rapid and transient changes in polyamine metabolism, termed the polyaminestress-response, may occur repeatedly in the brain after chronic intermittent stress (Gilad and Gilad, 2002). The repeated restraint stress induces oxidative stress. These alterations which may contribute to the deleterious effects on tissues were observed after restraint stress, the biochemical data on LPO, GPX, SOD, VIT E were clearly shown that restraint stress induces free radical generation which may lead to oxidative damage and onset of many cardiovascular and neurological diseases (Qairunnisa et al., 2014). The purpose of the present study was to investigate whether immobilization stress or elevated levels of the stress hormone corticosterone influence motor coordination. The experiments utilized standard immobilization stress models to asses motor coordination, performance after exposure to eugenol in restainer stress induced female Wistar albino rats.

In our study, there is an increase in the corticosterone level has been observed in the subacute restraint stress group when compared to treated and control groups. The elevated level has been decreased significantly in eugenol treated with subacute restraint stress group, but not up to the level of control and treated groups. Same findings have been observed in earlier studies (Flores et al., 1990; Clement et al., 1998). Both immobilization stress and swim stress induces an acute increase in corticosterone levels (Connor et al., 2000; Hall et al., 2001).

The behavioral responses to stress at a time interval, at which, corticosterone level returned to baseline level. It can also be speculated that the regular exposure to the stressor might have blunted the physiological stress response, thus reducing circulating corticosterone levels at the chronic time point. Subacute immobilization stress impairs accuracy of skilled movements in fore and hind limbs, and disrupt inter limb coordination. However, it did not affect skilled hind limb movements. The present data indicate that immobilization stress has a greater effect on motor coordination function. Inter limb coordination in skilled walking was disrupted only by immobilization stress, and immobilization led to greater deficits in reaching accuracy at time points than the other groups. Accordingly, a previous study suggested that immobilization stress is more salient than forced swim stress (Mercier et al., 2003).

The persistent motor deficits in stressed animals in the absence of elevated corticosterone levels suggest that stress associated behavioral alterations might affect motor performance independently of corticosterone. This assumption is supported by the difference of movement abnormalities found in stressed animals versus albino rats supplemented with corticosterone. An alternative mechanism by which stress can affect motor behavior might be due to stress associated changes in emotion. Repeated 
restraint stress, particularly augments anxiety and aggression (Sandi et al., 2001; Woodson et al., 2003).

Observations in our study were in accordance with earlier findings of behavioral and physiological changes in Long-Evans rats after immobilization (Faraday et al., 2002, 2003) and swim stress (Campbell et al., 2003). Furthermore, whereas a previous study indicated low stress-responsiveness in female Long-Evans rats (Faraday, 2002), the present findings highlight the significant impact of stress on the motor coordination function. Moreover, a previous study suggested that stress-induced learning impairments are less severe in females than in males and are independent of estrous cycle phase (Conrad et al., 2004). Accordingly, the present time course of reaching performance and analysis of the individual reaching performance revealed stable success rates. It has been suggested that the degree and duration of stress induced behavioral impairments depend on the type and duration of the adverse experience, and on the testing paradigm (Woodson et al., 2003).

The present study confirms these findings by showing improved accuracy and limb coordination associated with the control group. The response to eugenol treatment followed by restraint stress with an optimum effect on skilled-reaching success at $150 \mathrm{mg} / \mathrm{kg}$ b.wt dose. An acute dose of $150 \mathrm{mg} / \mathrm{kg}$ eugenol reduced corticosterone levels significantly than that of $100 \mathrm{mg}$ of eugenol, which is in accordance with data presented by Pohorecky et al. (1988). It is possible due to the anticonvulsant, antiinflammatory, antistress, antioxidant, and muscle relaxant properties (Atsumi et al., 2005; Laekeman et al., 2006; Muller et al., 2006) of eugenol. Thereby it reduces the corticosterone levels and increased movement accuracy in treated with stressed groups.

Kurian et al. (2006) stated that eugenol at $100 \mathrm{mg} / \mathrm{kg}$ exhibited a mild sedative effect that was evidenced by a reduction in endurance time at $30 \mathrm{~min}$ post dosing. However, there was no loss of motor coordination beyond that time, which is in accordance to the results of the study (Kurian et al., 2006). The impairment of performance on rotorod, narrow beam and a staircase appears to be a cumulative consequence of stress our results revealed that stress impaired performance on these tests. The stress-induced impairment of motor coordination was significantly ameliorated by eugenol in treated plus stressed rats it shows significantly more effective and there is no reduction in the endurance time, number of slip has been reduced in these groups. After a period of restraint stress, the animals were trained in the Rota rod showed depression in their activity. But after the administration of eugenol, the depression was eliminated gradually but it did not reach the control level.

This shows the anti-stressor effect of Eugenol. Since Eugenol has an antistressor effect, they can able to balance in the Rota rod when compared to the stressed animals. From the above observations we can conclude strongly that Eugenol has an antistressor effect. Eugenol thus acts at diverse sites that may be relevant to various neuropharmacological actions but the precise mechanism remains unclear. It substantially modulates brain functions by regulating voltage-gated cation and ligand gated ion channels, vanilloid receptor, and release of neurotransmitters.
Mainly excitatory receptors of glutamate i.e. N-methyl-D-aspartate (NMDA) and the inhibitory receptors for GABA as well.

\section{CONCLUSION}

Stress represents a significant modulator of motor system function in both the healthy and the damaged brain. Thus, it seems likely that stress also affects motor symptoms and recovery of disorders of the motor system. In the development of new therapeutic avenues these findings should be taken into consideration to improve treatment efficacy. While it is difficult to prevent stress from influencing the course of a neurological disease, interventions to reduce stress, such as experiential therapy, might represent useful complementary treatment.

To conclude, this study evaluates motor incoordination effects of eugenol by using the respective animal models. Though a few isolated studies to evaluate analgesic, anticonvulsant, antinociceptive and sedative effect of eugenol were done earlier, there was no single study like this one that tested a gamut of motor in coordination effects in a single study with pure eugenol. This study shows eugenol has mild motor co-ordination activity in restraint stress-induced animal models at the dose of $150 \mathrm{mg} / \mathrm{kg}$. b. wt. However, this could be possible due to the antistressor and antioxidant activity of eugenol. Further studies are required to explain precise mechanisms implicated in such a varied response in a wide range of doses and dosage combinations and to elucidate the potential therapeutic utility of eugenol.

\section{Financial support and sponsorship: Nil}

Conflict of Interests: There are no conflicts of interest.

\section{REFERENCE}

Amos S, Kolawole E, Akah P, Wambebe C, Gamaniel K. Behavioral effects of the aqueous extract of Guiera senegalensis in mice and rats. Phytomedicine. 2001; 8(5): 356-61.

Atsumi T, Fujisawa S, Tonosaki K. A comparative study of the antioxidant/ prooxidant activities of eugenol and isoeugenol with various concentrations and oxidation conditions. Toxicol In Vitro 2005; 19(8):1025-33.

Campbell $\mathrm{T}$, Lin $\mathrm{S}$, DeVries $\mathrm{C}$ and Lambert $\mathrm{K}$. Coping strategies in male and female rats exposed to multiple stressors. Physiol Behav. 2003; 78: 495- 504.

Chami F, Chami N, Bennis S, Trouillas J, Remmal A. Evaluation of carvacrol and eugenol as prophylaxis and treatment of vaginal candidiasis in an immunosuppressed rat model. J Antimicrob Chemother. 2004; 54(5): 909-14.

Connor, T.J., Kelliher, P., Shen, Y., Harkin, A., Kelly, J.P. and Leonard, B.E. (2000) Effect of subchronic antidepressant treatments on behavioral, neurochemical, and endocrine changes in the forced-swim test. Pharmacol. Biochem. Behav., 65, 591-597.

Conrad CD, Jackson JL, Wieczorek L, Baran SE, Harman JS, Wright RL and Korol DL. Acute stress impairs spatial memory in male but not female rats: influence of estrous cycle. Pharmacol Biochem Behav. 2004; 78: 569-579.

Clement HW, Kirsch M, Hasse C, Opper C, Gemsa D and Wesemann W. Effect of repeated immobilization on serotonin metabolism in different rat brain areas and on serum corticosterone. J Neural Transm. 1998; 105:1155-1170.

Dunham NW, Miya TS. A note on a simple apparatus for detecting neurological deficit in rats and mice. J Am Pharmac Assoc Sci. 1957; 46: 208-209. 
Faraday MM. Rat sex and strain differences in responses to stress. Physiol Behav. 2002; 75: 507-522.

Faraday MM, O'Donoghue VA and Grunberg NE. Effects of nicotine and stress on locomotion in Sprague-Dawley and Long-Evans male and female rats. Pharmacol. Biochem. Behav. 2003; 74: 325-333.

Flores C, Samaha AN and Stewart J. Requirement of endogenous basic fibroblast growth factor for sensitization to amphetamine. J Neurosci. 2000; 20:55.

Gilad GM, Gilad VH.Stress-induced dynamic changes in mouse brain polyamines. Role in behavioral reactivity.Brain Res. 2002 5;943(1):23-9.

Hall FS, Sundstrom JM, Lerner J and Pert A. Enhanced corticosterone release after a modified forced swim test in Fawn hooded rats is independent of rearing experience. Pharmacol Biochem Behav. 2001; 69: 629-634.

Irie Y, Itokazu N, Anjiki N, Ishige A, Watanabe K, Keung WM. Eugenol exhibits antidepressant-like activity in mice and induces expression of metallothionein-III in the hippocampus. Brain Res 2004; 1011:243-6.

Kolb B, Whishaw IQ. An observer's view of locomotor asymmetry in the rat. Neurobehav Toxicol Teratolog. 1985; 7:71-78.

Kurian R, Arulmozhi DK, Veeranjaneyulu A, Bodhankar SL. Effect of eugenol on animal models of nociception. Indian J Pharmacol. 2006; 38:341-345.

Lepicard et al., 2000 Lepicard E.M, Venault P, Perez-Diaz F, Joubert C, Berthoz A and Chapouthier G. Balance control and posture differences in the anxious BALB / cByJ mice compared to the non anxious C57BL/6J mice. Behav. Brain Res. 2000; 117: 185195.

Lepicard E.M, Venault P, Negroni J, Perez-Diaz F, Joubert C, Nosten- Bertrand M, Berthoz A and Chapouthier G. Posture and balance responses to a sensory challenge are related to anxiety in mice. Psychiatry Res. 2003; 118: 273-284.

Liebsch G, Montkowski A, Holsboer F and Landgraf R. Behavioural profiles of two Wistar rat lines selectively bred for high or low anxiety related behaviour. Behav. Brain Res. 1998; 94: 301310 .

Laekeman et al., 2006; Laekeman GM, Hoof LV, Haemers A, Vanden Berghe DA, Herman AG, Vlietinck AJ. Eugenol a valuable compound for in vitro animal research and worthwhile for further in vivo investigation. Phytother Res. 2006; 4(3): 90-6.

Marjan Aghajani, Mohammad Reza Vaez Mahdavi, Mohsen Khalili Najafabadi, Tooba Ghazanfari. The Effect of Social Stress on Chronic Pain Perception in Female and Male Mice. Plosone. 2012; 7: 10 e47218.

Maki BE and McIlroy WE. Influence of arousal and attention on the control of postural sway. J Vest Res. 1996; 6:53-59.

Mercier S, Frederic,Canini F, Buguet A, Cespuglio R, Martin S and Bourdon L. Behavioural changes after an acute stress: stressor and test types influences. Behav Brain Res. 2003; 139: 167-175.

Metz GA, Gonzalez CL, Piecharka DM and Whishaw IQ. Acute alcohol administration improves skilled reaching success in intact but not 6-OHDA dopamine depleted rats: a subsystems analysis of the motoric and anxiolytic effects of alcohol. Behav Brain Res. 2003; 142: 167-174.
Metz GA, Jadavji NM, Smith LK.Modulation of motor function by stress: a novel concept of the effects of stress and corticosterone on behavior. Eur J Neurosci. 2005; 22(5):1190-200.

Muller M, Pape HC, Speckmann EJ, Gorji A. Effect of eugenol on spreading depression and epileptiform discharges in rat neocortical and hippocampal tissues. Neuroscience. 2006;140(2): 743-51.

Prakash $\mathrm{P}$ and neelu gupta. Therapeutic uses of ocimum sanctum linn (tulsi) with a note on eugenol and its pharmacological actions. Indian J Physiol Pharmacol 2005; 49 (2) : 125-131.

Pruthi J.S. Species and Condiments, 1st ed, National Book Trust: New Delhi, India, 1976; 91-98.

Pohorecky LA, Cotler S, Carbone JJ and Roberts P. Factors modifying the effect of diazepam on plasma corticosterone levels in rats. Life Sci. 1988; 43:2159-2167.

Qairunnisa G, Gajalakshmi G, Purushothaman BA, Madhuri and Chandrasekhar M. A study to evaluate the effect of restraint stress on antioxidants status in rats. IJPSR. 2014; 5(1): 156-160.

Selye H. Stress and distress. Compr Ther. 1975a; 1: 9-13.

Selye H. Implications of stress concept. N. Y. State. J. Medical. 1975b; 75: 2139-2145.

Simiand J, Keane PE and Morre M. The staircase test in mice: a simple and efficient procedure for primary screening of anxiolytic agents. Psychopharmacology. 1984; 84: 48-53.

Singh DK andVerman R. Spectrophotometric Determination of Corticosteroids and Its Application in Pharmaceutical Formulation.Iranian Journal of Pharmacology and Therapeutics. 2008; 7: 61-65.

Swaroopa Marella and Sathyavelu Reddy K.Estimation of Lipid Peroxidation levels in Rat Brain During Stress Due to Withdrawal from Chronic Ethanol Consumption under the Influence of Ginger (Zingiber officinale Roscoe). Global Journal of Pharmacology. 2012; 6(3): 252-260.

Sandi C, Merino JJ, Cordero MI, Touyarot K and Venero C. Effects of chronic stress on contextual fear conditioning and the hippocampal expression of the neural cell adhesion molecule, ITS polysialation and L1. Neuroscience. 2001; 102: 329-339.

Treit D and Fundytus M. Thigmotaxis as a test for anxiolytic activity in rats. Pharmacol Biochem Behav. 1988; 31: 959-962.

Woodson JC, Macintosh D, Fleshner M and Diamond DM. Emotion-induced amnesia in rats: working memory-specific impairment, corticosterone-memory correlation, and fear versus arousal effects on memory. Learn Mem. 2003; 10: 326-336.

\section{How to cite this article:}

Selvan P, Malathi, Ravindran Rajan. Effect of 4-Allyl-2Methoxyphenol (Eugenol) on Motor Co-Ordination in Subacute Restraint Stress Induced Wistar Albino Rats. J App Pharm Sci, 2016; 6 (11): 120-125. 